\title{
Alterations in Cerebral Cortical Galanin Concentrations Following Neurotransmitter-Specific Subcortical Lesions in the Rat
}

\author{
Steven M. Gabriel, Peter J. Knott, and Vahram Haroutunian \\ Departments of Psychiatry at the Mount Sinai School of Medicine, New York, New York 10029 and the Bronx \\ Veterans Affairs Medical Center, Bronx, New York 10468
}

\begin{abstract}
Galanin is associated with multiple projection neurons, and its immunoreactivity in the cerebral cortex may be derived from diverse sources. We investigated the effects of subcortical lesions on cerebral cortical galanin concentrations. Lesions of the anterior noradrenergic bundle (ANB) comparably reduced cerebral cortical galanin and norepinephrine (NE) concentrations. The effects of the ANB lesions on galanin were immediate and became most pronounced 1 week later. Extensive unilateral lesions of the nucleus basalis of Meynert (NBM) decreased galanin concentrations, although not as markedly as after ANB lesions. The NBM lesions had no additional effect in the presence of an ANB lesion. Decreases in cerebral cortical galanin concentrations depended upon the extent and the duration of the NBM lesion and were not as pronounced as the decreases in markers of cholinergic activity. Acute treatments with physostigmine, which inhibit cerebral cortical $A C h E$, had no effect on galanin concentrations. The depletion of galanin following an NBM lesion was most pronounced within hours of the insult, while the depletion of ChAT following the same lesions required several days to develop. Cortical concentrations of galanin and 5- HT increased $1 \mathrm{hr}$ after dorsal raphe nucleus (DRN) lesions and then decreased $7 \mathrm{~d}$ later. Six weeks later, galanin concentrations recovered in the cerebral cortex despite the continued depletion of 5-HT. These studies suggest that a substantial portion of cerebral cortical galanin may derive from noradrenergic neurons and may be modulated by cortically-projecting ACh and 5-HT neurons.
\end{abstract}

[Key words: galanin, ACh, norepinephrine, serotonin, excitotoxin, nerve damage, Alzheimer's disease, dementia, neurodegeneration]

More than a decade since its isolation from the porcine intestine by Tatemoto and coworkers, galanin has been localized to many central nervous system nuclei in the rat (Tatemoto et al. 1983). This widely distributed neuropeptide is contained within neurons of the basal forebrain (Melander et al., 1985), noradrenergic neurons of the locus coeruleus (Skofitsch and Jacobowitz, 1985;

Received Nov. 14, 1994; revised Mar. 16, 1995; accepted Apr. 5, 1995.

We acknowledge the excellent technical assistance of Ms. Debra Lazarus, Ms. Rene Gluck, Mr. Elliot Fiber, and Ms. Ella-Mai McBorrough. This work was supported by AG10138 and AG02219. These data were presented in preliminary form at the Society for Neuroscience Meetings in 1993 and 1994.

Correspondence should be addressed to Steven M. Gabriel, Ph.D., Department of Psychiatry, Bronx Veterans Affairs Medical Center, 130 West Kingsbridge Road, Bronx, NY 10468.

Copyright $(1995$ Society for Neuroscience $0270-6474 / 95 / 155526-09 \$ 05.00 / 0$
Mclander et al., 1986b; Levin ct al., 1987), and serotonergic neurons of the raphe nuclei (Skofitsch and Jacobowitz, 1985; Melander et al., 1986b). Indeed, the association of galanin with the cholinergic neurons of the basal forebrain was among the earliest observations for the peptide (Melander et al., 1985). Galanin appears to modulate the classical neurotransmitters contained within these three subcortical areas. Thus, considerable evidence suggests that galanin inhibits cholinergic activity (Fisone et al., 1987; Mastropaolo et al., 1988). Within the locus coeruleus, pharmacological manipulations which deplete NE, stimulate the synthesis of both tyrosine hydroxylase and galanin, suggesting co-release and modulation (Austin et al., 1990; Gundlach et al., 1990a; Schultzberg et al., 1991). Galanin also appears to interact in a complex fashion with 5-HT neurons (Fuxe et al., 1988; Fone and Dixon, 1991; Martire et al., 1991).

Given its association within multiple cortically projecting subcortical neurons, it would be expected that galanin within the cerebral cortex would be derived from multiple sources. Clearly any disruption of these efferents would correspondingly affect cortical galanin. Yet, it has been reported that lesions of the NBM in the rat failed to reduce cerebral cortical galanin concentrations significantly, despite the reduction in markers of cortical cholinergic activity (Beal et al., 1988; Wenk and Rokaeus, 1988). We hypothesized that the apparent failure these localized excitotoxic lesions to reduce cerebral cortical galanin was related to the scattered distribution of the cholinergic cells in the basal forebrain and the variable anatomical relationship between galanin and ACh containing neurons across species (Johnston et al., 1981; Fibiger, 1982; Hedreen et al., 1984; Melander et al., 1985; Kowall and Beal, 1989; Walker et al., 1991; Mufson et al., 1993). In the following study, the concentrations of galanin in cerebral cortex of rats receiving NBM lesions of variable extent and duration were determined. Similar investigations of experimental lesions of locus coeruleus and dorsal raphe nucleus, where the localization of galanin with other neurotransmitters is more clearly delineated, have not been performed. We further hypothesized that lesions of these two groups of projection neurons would reveal significant contributions to the levels of galanin in the cortex. Therefore, additional studies were conducted to determine the degree to which cortical levels of galanin were influenced by the levels of these other, non-ACh-containing, classical neurotransmitters.

\section{Materials and Methods}

Animals and surgical treatments. Adult male Sprague-Dawley rats from Charles River Laboratories (Wilmington, MA) were housed in an AAALAC accredited vivarium $\left(25^{\circ} \mathrm{C}\right.$, lights on at $0700 \mathrm{hr}$ for $12 \mathrm{hr}$ ) with standard chow and tap water provided ad libitum, according to insti- 
tutionally approved protocols as specified in the NIH Guide to the Care and Use of Animals. All surgical procedures were performed under aseptic conditions using pentobarbital anesthesia $(45 \mathrm{mg} / \mathrm{kg}$, i.p.). Toxins were manually infused slowly over a $2-3$ min period. Postlesion survival times were $1 \mathrm{hr}$ to 6 weeks. Preliminary studies indicated that dual-site unilateral NBM lesions induced pronounced depletions in cortical cholinergic markers. Treatments consisted of sham operations, double unilateral or single bilateral infusions of NMDA into the NBM to lesion the cholinergic neurons, single or bilateral infusions of 6-hydroxydopamine (6OHDA) into the ANB to lesion the noradrenergic neurons, concurrent ANB and NBM lesions or, lastly, midline infusions of $(5,7)$-dihydroxytryptamine (DHT) into the DRN to lesion the serotonergic neurons.

For single-site unilateral and single-site bilateral lesions of the NBM, $50 \mathrm{nmol} \mathrm{NMDA} / \mu$ l were infused per site at the following coordinates: $-0.3 \mathrm{~mm}$ bregma, $\pm 3.0 \mathrm{~mm}$ lateral, divide dose between $-8.1 \mathrm{~mm}$ $(0.6 \mu \mathrm{l}),-7.8 \mathrm{~mm}(0.2 \mu \mathrm{l}),-7.5 \mathrm{~mm}(0.2 \mu \mathrm{l})$ from skull surface. Half (or partial) dose NMDA lesions were placed at the same coordinates as above, but with half the volume infused. The double-site unilateral lesions of the NBM were produced with $50 \mathrm{nmol} N \mathrm{NDA} / \mu \mathrm{l}$ infused at the following two sets of coordinates: (1) $0.0 \mathrm{~mm}$ bregma, $\pm 2.8 \mathrm{~mm}$ lateral, divide dose between $-8.3 \mathrm{~mm}(0.6 \mu \mathrm{l}),-8.1 \mathrm{~mm}(0.2 \mu \mathrm{l}),-7.8$ $\mathrm{mm}(0.2 \mu \mathrm{l})$ from skull surface, and (2) $-0.7 \mathrm{~mm}$ bregma, $\pm 3.2 \mathrm{~mm}$ lateral, divide dose at $-8.0 \mathrm{~mm}(0.6 \mu \mathrm{l}),-7.8 \mathrm{~mm}(0.2 \mu \mathrm{l}),-7.5 \mathrm{~mm}$ $(0.2 \mu \mathrm{l})$ from skull surface. Lesioning of the ANB was accomplished by the injection of $4 \mu \mathrm{g} / \mu \mathrm{l}$ 6-OHDA free base at the following coordinates: $-5.0 \mathrm{~mm}$ bregma, $\pm 1.0 \mathrm{~mm}$ lateral, divide dose $-6.0 \mathrm{~mm}(1$ $\mu \mathrm{l}),-5.5 \mathrm{~mm}(1 \mu \mathrm{l})$ from skull surface. Finally, for lesions of the DRN, $50 \mathrm{nmol} / \mu \mathrm{l}$ DHT was infused at the following coordinates: $+1.5 \mathrm{~mm}$ IAC, $3 \mathrm{~mm}$ lateral, $-7.0 \mathrm{~mm}$ below skull, at $27^{\circ}$ angle to avoid the ventricular and sinus systems. For all lesions, the upper incisor bar was at the level of the intra auricular line. Controls (or shams) consisted of the unlesioned contralateral side within the same animal for unilateral lesions, unilateral or bilateral sham operations to the appropriate nucleus or tract in a separate group of rats, or unoperated groups of rats. Sham operations consisted of anesthesia with either the simple opening of the skull or placement of a vehicle-containing needle $1 \mathrm{~mm}$ above the lesion site. For all unilateral lesions, the choice of lesion side was varied randomly.

Tissue processing and neurochemical measurements. Following lesions and treatments, rats were decapitated and the brains removed and placed on a cold plate for the dissection of the of the frontal cerebral cortex (the anterior two-thirds of the cortex superior to the rhinal fisher). Dissected samples were frozen and pulverized under cryogenic conditions and prepared as homogenous aliquots for all quantitative measures. Rat galanin-like immunoreactivity (galanin) was quantified using a previously characterized radioimmunoassay (Gabriel et al., 1993). The assay has a sensitivity of $4 \mathrm{pg}$, an $\mathrm{ED}_{50}$ of $55 \mathrm{pg}$, an intra-assay variance of $7 \%$, and an interassay variance of $18 \%$. Protein was determined in the acid-insoluble extracted sample precipitate (Lowry et al., 1951). The concentrations of the cholinergic activity markers, ChAT and AChE, were determined using previously described methods (Fonnum, 1975; Johnson and Russell, 1975). Tissue concentrations of biogenic amines were quantified by high-pressure liquid chromatography with electrochemical detection (Haroutunian et al., 1990a). All reagents unless otherwise noted were obtained from Sigma Chemicals (St. Louis, MO).

Statistical analyses and experimental design. Data wcre analyzed using analysis of variance for general linear models. Tukey's HSD for unequal sample sizes were used for post hoc comparisons of individual group means with $p<0.05$ considered significant. When data from both cerebral cortical hemispheres of rats receiving bilateral or midline lesions, but no concurrent unilateral lesion treatment, were collapsed as a single data point, analysis of variance was performed to verify the lack of a lateralized effect. Percentage declines were calculated relative to the appropriate control sample, that is, contralateral to a unilateral lesion or ipsilateral to that side of a sham-operated rat.

This study consisted of five experiments which focus on three subcortical neuronal systems that project to the frontal cerebral cortex cholinergic, noradrenergic and serotonergic. The first three experiments focused on parameters affecting frontal cerebral cortical cholinergic activity and galanin concentrations after lesions of the NBM. In experiment 1 , rats were subjected to double-site unilateral excitotoxin lesions of the NBM. Just prior to sacrifice, at $7 \mathrm{~d}$ postlesion, these rats were further treated by subcutaneous injection with saline, scopolamine $(5$ $\mathrm{mg} / \mathrm{kg}$ at $90 \mathrm{~min}$ and $45 \mathrm{~min}$ before sacrifice) or physostigmine (0.5 $\mathrm{mg} / \mathrm{kg}$ at $90 \mathrm{~min}$ plus $0.25 \mathrm{mg} / \mathrm{kg}$ at $45 \mathrm{~min}$ before sacrifice). In experiment 2 , rats were subjected to sham operations, half-dose, singlesite, or double-site unilateral lesions of the NBM with NMDA and sacrificed at 1 week after treatment. Experiment 3 consisted of doublesite unilateral lesions of the NBM of varying length duration. In experiment 4 , frontal cerebral cortical concentrations of biogenic amines and galanin were determined at different times after ANB or DRN lesions, which affect the locus coeruleus and raphe nuclei, respectively. Based on the pronounced changes in galanin seen after ANB lesions and previous studies suggesting an interaction between noradrenergic and cholinergic systems, experiment 5 consisted of combinations of ANB and NBM lesions in rats allowed to survive for 3 weeks.

\section{Results}

Experiment 1: the effects of NBM lesions plus treatment with cholinomimetic agents on frontal cerebral cortical cholinergic activity and galanin concentrations

Seven days after a double unilateral lesion of the NBM saw cortical deficits in the activities of the two cholinergic activity markers and in the concentrations of galanin. Physostigmine only inhibited AChE activity, and scopolamine had no effect on any neurochemical measure. Comparisons of a measure in a lesioned hemisphere to its corresponding unlesioned contralateral hemisphere were similar to comparisons of a measure in a lesioned hemisphere to the same side of a sham-operated animal. For AChE activity (Fig. 1, top), significant effects were found for drug treatment $\left(F_{2,65}=502.8, p<0.0001\right)$, lesion $\left(F_{1,65}=\right.$ $264.8, p<0.0001)$, the laterality of the sample relative to the lesion side $\left(F_{1,65}=308.9, p<0.0001\right)$, plus all interactions (all $p<0.001)$. The NBM lesions reduced cortical AChE activity by more than $65 \%$ regardless of the cholinomimetic treatment. Blockade of $\mathrm{AChE}$ by physostigmine also induced a $65 \%$ reduction in AChE activity. When physostigmine was administered to the NBM lesioned rats, AChE activity was reduced by $89 \%$.

The NBM lesions reduced ChAT activity by greater than $55 \%$ regardless of the cholinomimetic treatment (Fig. 1, middle). This was evidenced by analysis of variance as significant effects for lesion $\left(F_{1,65}=169.9, p<0.0001\right)$, the laterality of the sample relative to the lesion $\left(F_{1,65}=182.6, p<0.0001\right)$, the interaction of lesion with sample laterality $\left(F_{1,65}=138.2, p<0.0001\right)$. Like ChAT activity, the NBM lesions reduced galanin concentrations regardless of the cholinomimetic treatment, although not as profoundly (20\%; Fig. 1, bottom). This was evidenced by analysis of variance as significant effects for lesion $\left(F_{1,65}=15.77, p>\right.$ $0.0002)$, laterality of the sample relative to the lesion side $\left(F_{1,65}\right.$ $=9.47, p>0.0033)$ and their interaction $\left(F_{2,65}=6.77, p>\right.$ 0.0120 ).

\section{Experiment 2: the effects of NBM lesion size on frontal cerebral cortical ChAT activity and galanin concentrations}

These three types of NBM lesions approximate a lesion size (or dose) response on ChAT activity and galanin concentrations. The magnitude of the decrease in ChA'l activity, and to a lesser extent galanin concentrations, were dependant on the size of the NBM lesion. This experiment was performed as two individual studies with the average neurochemical measures being different for the two studies. For ChAT activity (Fig. 2, top), all three lesions produced significant contralateral to ipsilateral reductions. For galanin concentrations (Fig. 2, bottom) the single and double unilateral NBM lesions produced significant contralateral to ipsilateral reductions.

These dala are summarized in Table 1 as percentage decreases of the ipsilateral (lesioned) cortical hemisphere relative to the 

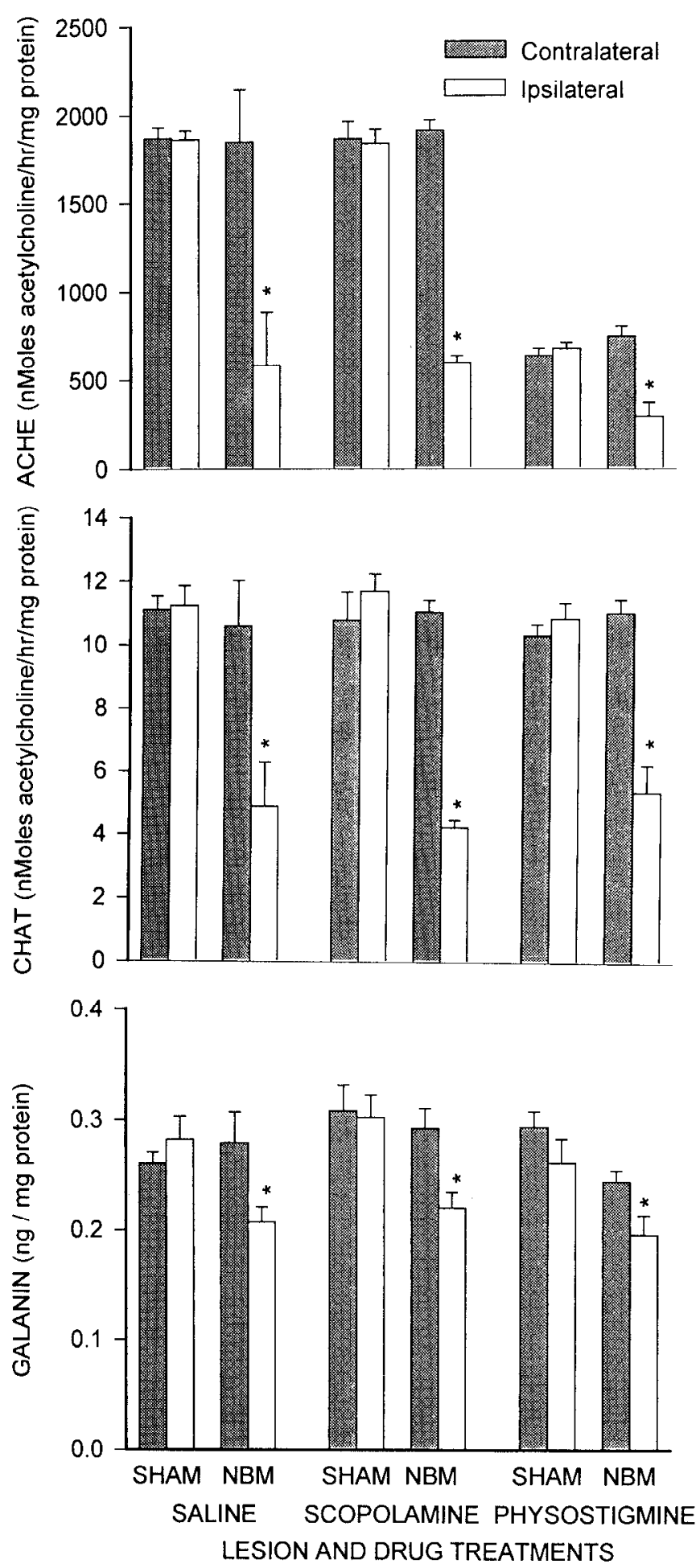

Figure 1. Activities for AChE and ChAT and concentrations for galanin in the frontal cerebral cortex at $7 \mathrm{~d}$ following double-site unilateral lesions of the NBM with presacrifice treatment with saline or cholinergic drugs. The top panel depicts $\mathrm{AChE}$ activity, the middle panel depicts ChAT activity, while the bottom panel depicts galanin concentrations. $*, p<0.05$ compared to the unlesioned contralateral hemisphere for the same treatment, as well as compared to the same hemisphere from sham-operated animals. Bars represent the mean $\pm \mathrm{SEM}$ of $6-10$ rats.
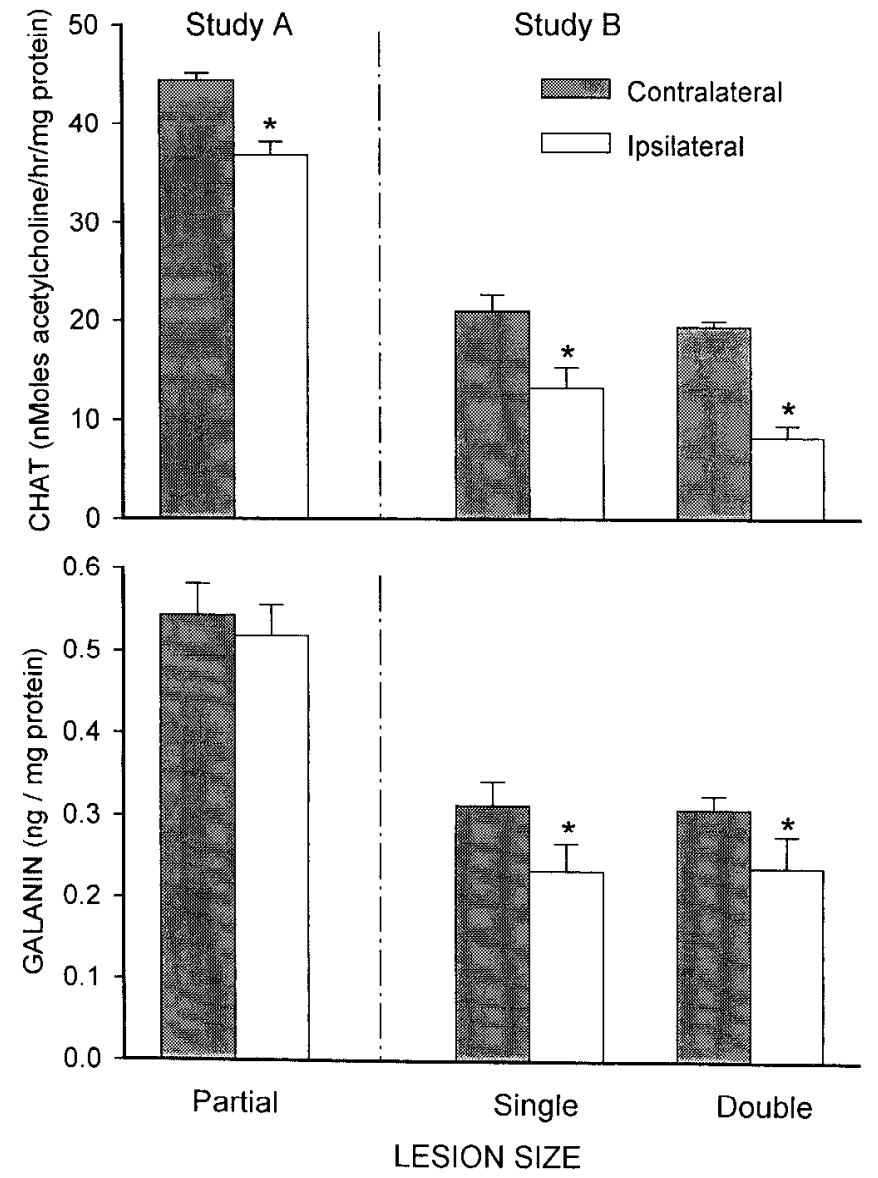

Figure 2. Frontal cerebral cortical ChAT activity and galanin concentrations $7 \mathrm{~d}$ after unilateral NBM lesions of varying size. The top panel depicts ChAT activity, while the bottom panel depicts galanin concentrations. ${ }^{*}, p<0.05$ decrease contralateral to ipsilateral. Bars represent the mean \pm SEM of $6-10$ rats. These data are summarized as percentage decreases in Table 1 .

contralateral (unlesioned) cortical hemisphere to better illustrate the effect of lesion size. For all three lesions, ChAT enzymatic activity was affected to a greater extent relative to galanin. Analysis of variance revealed significant effects of the three lesions $\left(F_{2,19}=14.75, p<0.0002\right)$ in ChAT activity. For galanin, trend level significance was found for the effects of the three lesion treatments $\left(F_{2,17}=3.31, p<0.06\right)$. However, this only indicates that the relatively small percentage decreases in galanin for the three lesions did not differ from one another and not that the lesions themselves had no effect.

Table 1. Percentage decreases, contralateral to ipsilateral, in CHAT activity and galanin concentrations in the cerebral cortex 1 week after unilateral NBM lesions of varying size

\begin{tabular}{llc} 
Lesion type & CHAT & Galanin \\
\hline Partial & $17.3 \pm 5.7^{*}$ & $7.5 \pm 4.4$ \\
Single & $36.0 \pm 7.9^{*}$ & $26.3 \pm 7.6^{*}$ \\
Double & $57.4 \pm 5.7^{*}$ & $31.2 \pm 9.7^{*}$
\end{tabular}

Values represent MEAN \pm SEM.

* Significant, $p<0.05$, contralateral to ipsilateral decrease 


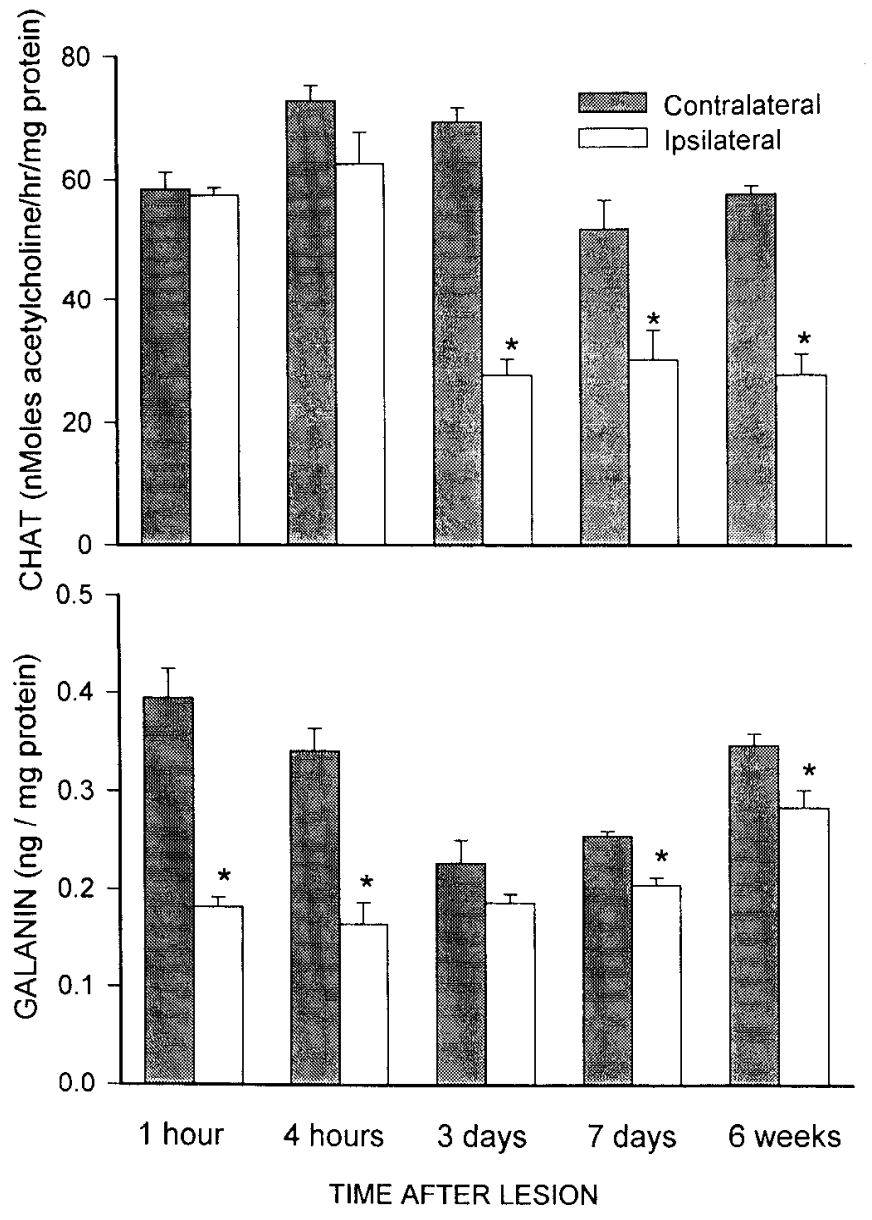

Figure 3. Frontal cerebral cortical ChAT activity and galanin concentrations at varying times following double-site lesioning of the NBM. The top panel depicts ChAT activity, while the bottom panel depicts galanin concentrations. *, $p<0.05$, decrease contralateral to ipsilateral. Bars represent the mean \pm SEM of 6-10 rats. These data are summarized as percentage decreases in Table 2 .

Experiment 3: the effects of varying times following NBM lesions on frontal cerebral cortical ChAT activity and galanin concentrations

Time after a double unilateral NBM lesion significantly influenced the resulting cortical ChAT activity and galanin concentrations. For ChAT (Fig. 3, top), the excitotoxin lesion had no immediate effect, but reduced that cholinergic activity marker at the later time points. This was evident as significant effects of postsurgical survival $\left(F_{4.79}=31.82, p>0.0001\right)$, lesion laterality $\left(F_{1,70}=158.38, p>0.0001\right)$ and their interaction $\left(F_{4,79}=\right.$ 17.40, $p>0.0001$ ). In contrast galanin concentrations (Fig. 3, bottom) were maximally depleted $1 \mathrm{hr}$ after the NMDA injection and less affected at the later time points. This was evident as significant effects of postsurgical survival $\left(F_{4,89}=8.27, p>\right.$ $0.0001)$, lesion laterality $\left(F_{1,89}=64.53, p>0.0001\right)$ and their interaction $\left(F_{4.89}=8.74, p>0.0001\right)$.

These data are summarized in Table 2 as percentage decreases of the ipsilateral (lesioned) cortical hemisphere relative to the contralateral (unlesioned) cortical hemisphere to better illustrate the varying effects of time on ChAT versus galanin. This was expressed for ChAT, as a significant effect of postsurgical survival interval $\left(F_{4,39}=31.4, p>0.0001\right)$. For galanin the percentage decreases at 1 and $3 \mathrm{hr}$ were greater in magnitude com-
Table 2. Percentage decreases, contralateral to ipsilateral, in CHAT activity and galanin concentrations in the frontal cerebral cortex at varying times following double-site unilateral NBM lesions

\begin{tabular}{lcl}
$\begin{array}{l}\text { Time after } \\
\text { lesion }\end{array}$ & CHAT & Galanin \\
\hline $1 \mathrm{hr}$ & $1.9 \pm 3.8$ & $52.6 \pm 3.5^{*}$ \\
$4 \mathrm{hr}$ & $14.0 \pm 5.6$ & $50.7 \pm 9.2^{*}$ \\
$3 \mathrm{~d}$ & $59.8 \pm 3.8^{*}$ & $11.7 \pm 10.2$ \\
$7 \mathrm{~d}$ & $53.5 \pm 3.4^{*}$ & $18.2 \pm 3.5^{*}$ \\
6 weeks & $51.5 \pm 6.4^{*}$ & $17.2 \pm 6.8^{*}$
\end{tabular}

Values represent MEAN \pm SEM.

* Significant, $p<0.05$, contralateral to ipsilateral decrease.

pared to the later time intervals. By analysis of variance, this was expressed as a significant effect of postsurgical survival interval $\left(F_{4.34}=7.13, p>0.0004\right)$.

\section{Experiment 4: the effects time after ANB or DRN lesions on frontal cerebral cortical biogenic amine and galanin concentrations}

The variable effects of time after a bilateral ANB or a midline DRN lesion on galanin concentrations in the cortex are shown in Figure 4. Galanin concentrations in sham-operated rats were comparable at the three time points, while each lesion had distinct effects on galanin concentrations that varied with time. As such, analysis of variance revealed significant effects of lesion $\left(F_{2,88}=66.22, p<0.0001\right)$, time $\left(F_{2,88}=36.85, p<0.0001\right)$, and their interaction $\left(F_{4,88}-11.87, p<0.0001\right)$. The 6-OHDA infusion produced a $17 \%$ decline in galanin concentrations at 1

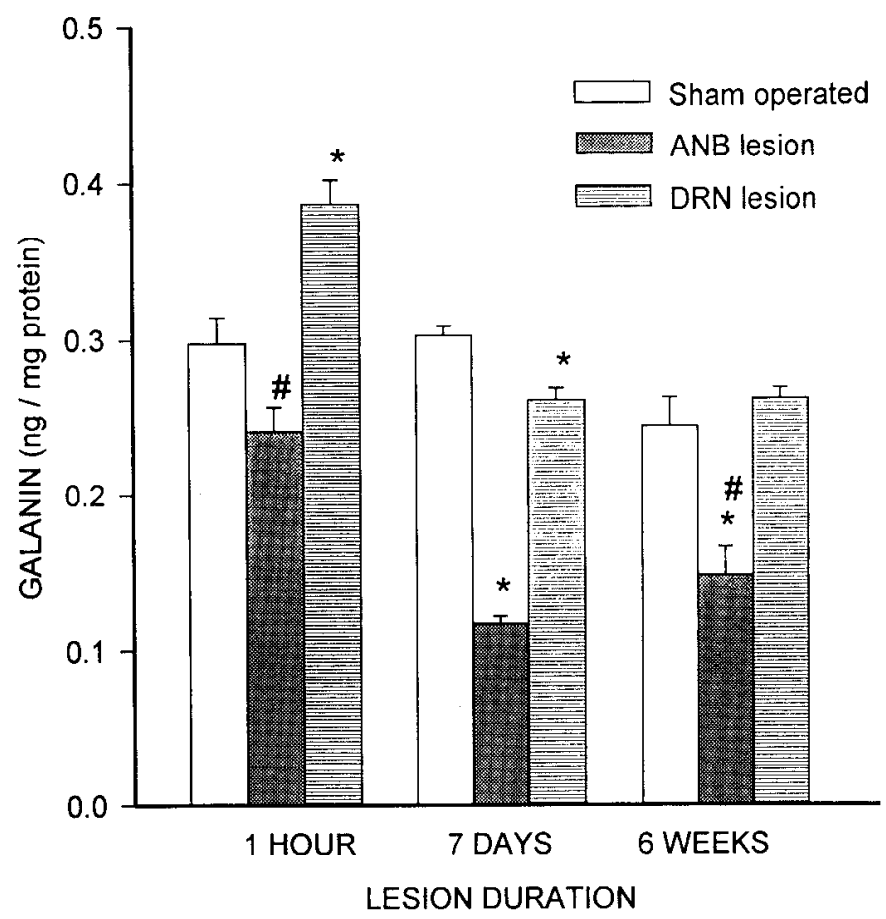

Figure 4. Frontal cerebral cortical galanin concentrations at varying times following bilateral ANB or a midline DRN lesions. ${ }^{*}, p<0.05$ versus sham-operated control at the same time point; \#, $p<0.05$ for percentage decline in galanin versus the percentage decline at $7 \mathrm{~d}$. Bars represent the mean \pm SEM of 6-10 rats. 


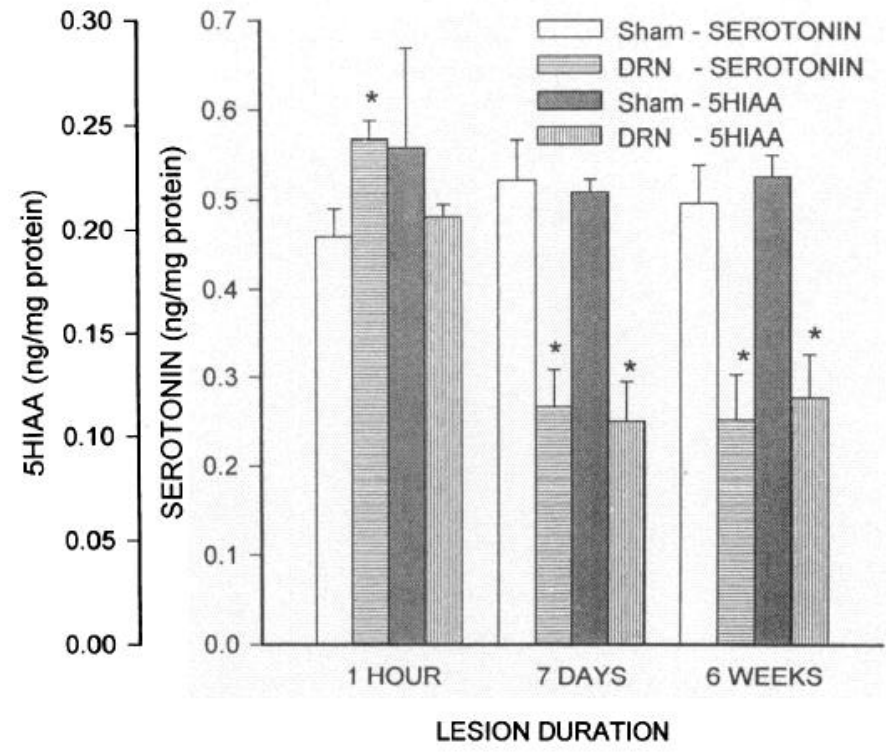

Figure 5. Frontal cerebral cortical 5-HT and 5HIAA concentrations at varying times following a midline lesion of the DRN. ${ }^{*}, p<0.05$ compared to sham-operated controls. Bars represent the mean \pm SEM of $6-10$ rats.

hr that was of trend level significance. At 7 days and 6 weeks after the 6 OHDA, galanin concentrations were reduced $61 \%$ and $39 \%$. The DHT infusion produced multiphasic effects on galanin. One hour after DHT infusion into the DRN, galanin concentrations were increased $30 \%, 7 \mathrm{~d}$ after DHT, the concentrations of galanin were decreased $14 \%$ and at the longest postlesion time of 6 weeks, galanin concentrations were no different than controls.

The midline DRN lesions also had effects on cerebral cortical 5-HT and 5-hydroxy-indoleacetic acid (5-HIAA) concentrations that varied with time (Fig. 5). Like galanin, 5-HT concentrations were increased (23\%) $1 \mathrm{hr}$ after the DHT infusion and decreased (49\%) $7 \mathrm{~d}$ after the DHT infusion, but remained decreased $(49 \%)$ 6 weeks after the DHT infusion. For 5-HT, significant effects were found for lesion $\left(F_{1,65}=11.08, p<0.002\right)$, time $\left(F_{2,65}=\right.$ $4.64, p<0.01)$, and their interaction $\left(F_{2.65}=8.80, p<0.0004\right)$. The DHT infusion had no effect on 5-HIAA concentrations at $1 \mathrm{hr}$ after infusion, but concentrations of 5-HIAA were decreased $51 \%$ and $47 \% 7 \mathrm{~d}$ and 6 weeks after DHT infusion, respectively. These differences in 5HIAA concentrations were supported by significant effects for lesion $\left(F_{1,64}=20.95, p<\right.$ $0.0001)$ and time $\left(F_{2,64}=3.96, p<0.03\right)$.

\section{Experiment 5: the effects of combinations of ANB with NBM lesions on frontal cerebral cortical ChAT activity, galanin and norepinephrine concentrations}

This experiment consisted of two separate studies. In the first study, bilateral ANB lesions were combined with double unilateral NBM lesions in an incomplete block design that was analyzed as a two-way ANOVA. The bilateral ANB lesion had no effect on ChAT activity, while the unilateral NBM lesion produced a significant, approximately $50 \%$ contralateral to ipsilateral, deficit (Fig. 6, left). This was evidenced as significant effects of the lesion group $\left(F_{2,42}=61.20, p<0.001\right)$, brain hemisphere relative to the NBM lesion side $\left(F_{1,42}=33.02, p<0.001\right)$ and their interaction $\left(F_{2.42}=35.41, p<0.001\right)$. In contrast, the bilateral ANB lesion significantly reduced galarin concentra- tions by $65 \%$, while no effects were attributable to the unilateral NBM lesion (Fig. 6 , middle; $F_{2,43}=141.73, p<0.0001$ for the lesion group effect). Like galanin, the bilateral ANB lesion significantly reduced NE concentrations $(85 \%)$, while no effects were attributable to the unilateral NBM lesion (Fig. 6 , right; $F_{2,40}$ $=154.03, p<0.0001$ for the lesion group effect). Lastly, neither ANB nor ANB plus NBM lesions had significant effects on the concentrations of dopamine, dihydroxy-phenyl-acetic acid, 5 -HT or 5-HIAA concentrations in the same cerebral cortex samples (data not shown).

Data from a second more extensive study of the interactions between ANB and NBM lesions on cerebral cortical galanin were also modeled as an incomplete block design and analyzed as a two-way analysis of variance. The ANB (54\%) and NBM $(14 \%)$ lesions alone each reduced galanin concentrations in magnitudes that were comparable to the results of the above described experiments. When combined, the larger effect of the ANB lesion, whether unilateral or bilateral, obscured any smaller effect of the NBM lesion. This was evidenced by analysis of variance as significant effects for lesion group $\left(F_{3.65}=54.63, p\right.$ $<0.0001)$, unilateral lesion side $\left(F_{1.65}=44.92, p<0.0001\right)$, and their interaction $\left(F_{3.65}=15.08, p<0.0001\right)$.

\section{Discussion}

The present study confirms, using site-specific lesions, that cerebral cortical galanin is influenced by and perhaps localized to multiple long tract cortically projecting neurons. Galanin has been described in projection neurons, interneurons and neurosecretory cells, but has yet to be persuasively described in intrinsic cortical perikarya (Skofitsch and Jacobowitz, 1985; Kowall and Beal, 1989; Cortes et al., 1990a; Gundlach et al., 1990b; Evans et al., 1992). The present data would suggest that large portions of cerebral cortical galanin immunoreactivity, if not the majority, are derived from subcortical efferents. Alternatively, the decreases in galanin following subcortical lesions may reflect the influence of these circuits on galanin containing cells that are not fully described. That galanin-expressing cells remain to be described more than a decade after its isolation reflects the complexity of a peptide contained within multiple overlapping neuronal targets. The use of colchicine has further complicated matters (Melander et al., 1985; Skofitsch and Jacobowitz, 1985; Melander et al., 1986a; Senut et al., 1989; de Bilbao et al., 1991; Pasqualotto and Vincent, 1991). This time honored reagent for enhancing the perikaryal localization of peptides has effects on neuropeptide gene expression that go beyond its action on axonal transport (Cortes et al., 1990a). Indeed, galanin is expressed in glial elements after colchicine treatment (Xu et al., 1992), perhaps reflecting a general response of the peptide to neuronal damage.

Of the three neuronal systems investigated, the lesioning of cortically projecting noradrenergic neurons appears to have the most profound and potentially the most direct effect on cerebral cortical galanin. After lesions of the ANB, galanin concentrations were rapidly depleted and remained so for up to six weeks. These changes were comparable in magnitude and paralleled the depletion of NE, suggesting that the lost peptide was contained within degenerating noradrenergic neurons. The reductions in NE following intracerebral 6OHDA treatment were also comparable to previous findings (Connor et al., 1992). Several recent investigations suggest that galanin in the locus coeruleus is coregulated with tyrosine hydroxylase in noradrenergic neurons (Austin et al., 1990; Gundlach et al., 1990a; Schultzberg et al., 


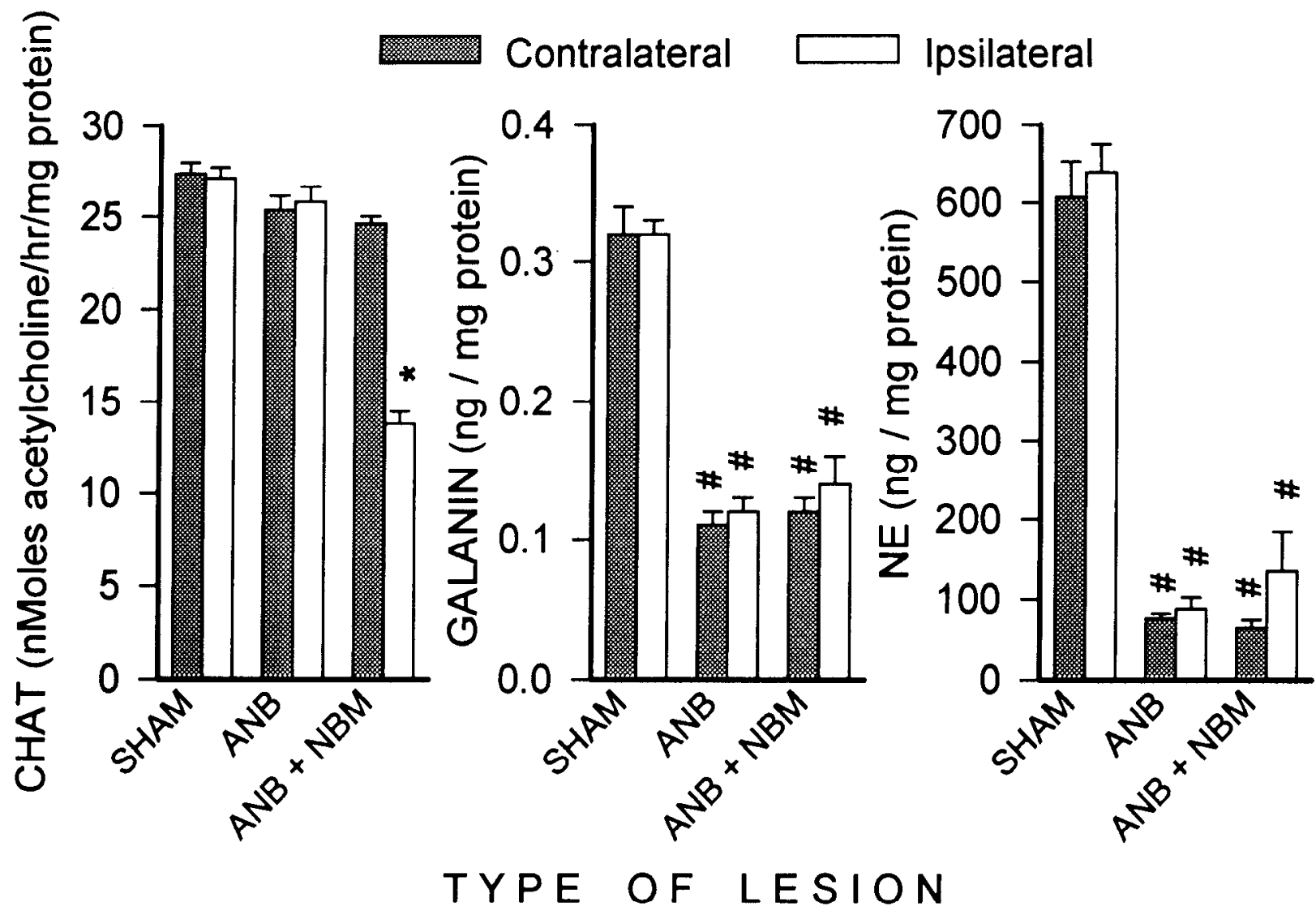

Figure 6. Frontal cerebral cortical ChAT activity, galanin concentrations, and NE concentrations 3 weeks after a bilateral ANB lesion or its combination with a double-site unilateral NBM lesion. The left panel depicts ChAT activity, the middle panel depicts galanin concentrations, while the right panel depicts NE concentrations. ${ }^{*}, p<0.05$ compared to contralateral (unlesioned) side for that treatment. \#, $p<0.05$ compared to the same side of sham-operated rats. The bars represent the mean \pm SEM of $6-10$ rats per treatment group.

1991). The present study extends these findings by showing that lesions of noradrenergic neurons have actions on galanin at distal projection sites. While pharmacologically administered galanin appears to inhibit the firing of locus coeruleus neurons (Seutin et al., 1989), it is not known what function galanin may have within these noradrenergic neurons or whether galanin may modulate noradrenergic-mediated behaviors. Within the hypothalamic paraventricular nucleus, galanin and neuropeptide $Y$ appear to have interrelated actions on feeding behaviors (Leibowitz, 1989). Perhaps the two neuropeptides work in a similar fashion with regards to locus coeruleus neurons.

Although the effects of double-site unilateral NBM lesions were considerably less pronounced than the effects of ANB lesions on cerebral cortical galanin concentrations, they were nevertheless repeatedly observed. The magnitude of this depletion was comparable to previously observed nonsignificant reductions in the peptide following single-site NBM lesions (Bcal ct al., 1988; Wenk and Rokaeus, 1988), suggesting greater group variance in the earlier studies. Galanin concentrations in the cerebral cortex are less than one-tenth that seen whole hypothalamic extracts (Gabriel, unpublished observations). The galanin radioimmunoassay in the present study was specific for rat galanin and more sensitive than the previous two radioimmunoassays (Beal et al., 1988; Wenk and Rokaeus, 1988; Gabriel el al., 1993). Further, the reductions in ChAT activity after double-site unilateral NBM lesions were greater than those observed following single-site NBM lesions previously, suggesting a more ex- tensive basal forebrain lesion (Beal et al., 1988; Wenk and Rokaeus, 1988). Thus, the parameters of the radioimmunoassay and the extent of the NBM lesion are important components in determining reductions in the already low concentrations of this peptide in the rat cerebral cortex. The second and third experiments of the present study confirm that the extent of the basal forebrain lesion and the time after the lesion are crucial variables in determining the reduction in cerebral cortical galanin concentrations. In the case of combined NBM and ANB lesions, it is likely that the contribution of the small NBM lesion effect is masked by the presence of a massive ANB lesion effect.

Yet, the reductions in cortical galanin after NBM lesions are a surprising result. Evidence for colocalization of galanin and acetylcholine varies according to the specific nuclei and species. In monkeys, galanin is expressed within magnocellular neurons of the NBM (Walker et al., 1989), while in the human the peptide is visualized in neuronal fibers (Mufson et al., 1993) and parvacellular neurons (Walker et al., 1991) but within very few magnocellular neurons of the NBM (Chan Palay, 1988a; Walker et al., 1991). Much of this galanin immunoreactivity in man may derive from a fiber tract originating in the amygdala (Mufson et al., 1993). Like man, in the rat, galanin, though expressed, does not appear to substantially localize within cholinergic cells of the NBM (Melander et al., 1985, 1986b; Gundlach et al., 1990b; Pasqualotto and Vincent, 1991; Unger and Schmidt, 1993). Rather, galanin and cholinergic activity markers are extensively colocalized in the septum and diagonal band (Senut et al., 1989; 


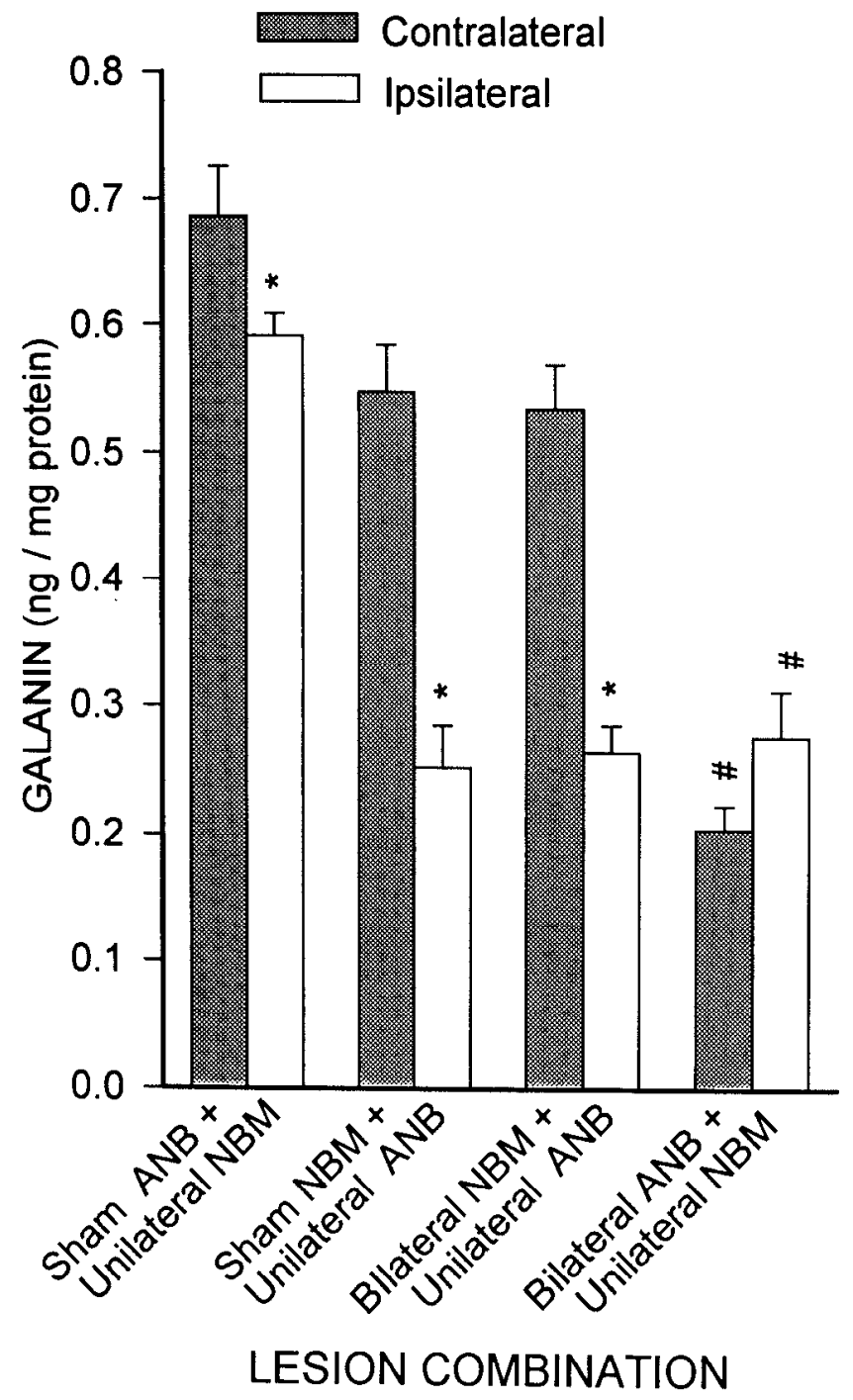

Figure 7. Frontal cerebral cortical galanin concentrations 3 weeks after combinations of ANB and double unilateral NBM lesions. ${ }^{*}, p<$ 0.05 ipsilateral side compared to the contralateral for the same treatment; \#, $p<0.05$ compared to the same side of the double unilateral NBM plus sham ANB lesions group. Bars represent the mean \pm SEM of $6-10$ rats.

de Bilhan et al., 1991). Predictably, excitotoxic lesions of the medial septal nucleus in the rat reduces galanin by $30-60 \%$ in the hippocampus (Beal et al., 1988; Wenk and Rokaeus, 1988).

Cortically projecting cholinergic afferents originate in a broad band that includes the NBM, globus pallidus, ventral palladium, the entopeduncular nucleus and the lateral preoptic area (Johnston et al., 1981; Fibiger, 1982; Hedreen et al., 1984). While the larger basal forebrain lesions of the present study contributed to the reductions in cerebral cortical galanin, current anatomical evidence does not support the contention that this diminished galanin immunoreactivity was contained within degenerating cholinergic cells. It is possible that the present double unilateral NBM lesions may have impinged upon cholinergic neurons of the horizontal limb of the diagonal band of Broca, which do contain galanin (de Scnut et al., 1989; Bilbao ct al., 1991; Pasqualotto and Vincent, 1991). Conversely, previous observations of cortically projecting galanin and ChAT containing cells in the in the horizontal limb of the diagonal band of Broca may have included cells from adjacent, ambiguously demarcated nuclei (Senut et al., 1989; Pasqualotto and Vincent, 1991). Although the diminished galanin may be contained within noncholinergic NBM neurons (Walker et al., 1989; Kitchener and Diamond, 1993 ) or cortically projecting fibers of passage (Nieuwenhuys, 1985), the specificity of the excitotoxin lesion make this possibility unlikely (Harrington et al., 1994). Aside from question of colocalization, it is possible that cortically projecting cholinergic neurons may exert a modulatory effect on galanin contained within other cortical elements.

The possibility that cholinergic neurons modulate galanin in other cells is suggested by the dissociation between galanin concentrations, which markedly declined in the hours immediately following the NBM lesion, and ChAT activity, which gradually declined over time. Because the NBM lesion is induced by the excitotoxin, NMDA, it is likely that massive cholinergic stimulation of the cortex commences following the NMDA injection. Most behavioral and pharmacologic studies indicate that galanin acts to inhibit cholinergic activity and to modulate cholinergicmediated bchaviors (Fisonc ct al., 1987; Robinson and Crawley, 1993). Because of the multiple neuronal cell types that contain galanin, the effects of galanin on cholinergic neurons may well reflect interneuronal as well as autoregulatory actions. These previous studies (Fisone et al., 1987; Robinson and Crawley, 1993) would suggest that pronounced reductions in galanin following excitotoxin infusion represents peptide release to compensate for cholinergic overstimulation. Conversely, blockade of galanin release or the administration of specific antagonists may serve as a means to enhance cholinergic function. However, as demonstrated in the first experiment (Fig. 1), less pronounced pharmacological manipulations of cholinergic neurons do not acutely change tissue concentrations of galanin.

The final lesion studied here, that of the DRN, produced the most fluctuating effect on galanin. Both galanin peptide and 5-HT increased in concentrations acutely following the DHT infusion. It is likely that serotonergic neuronal activity, and perhaps galanin neuronal activity, was inhibited at this acute time point. Since sham operations were performed, this inhibition is not likely due to a nonspecific effect of anesthesia. Like the NBM lesions, at $7 \mathrm{~d}$ the observed reduction in cerebral cortical galanin after DRN lesions was small (14\%) relative to its cocontained classical neurotransmitter $(49 \%)$ and to galanin after an ANB lesion of similar duration. The depletion of 5-HT concentrations after a DRN lesion was comparable to that seen in previous studies (Dekker and Thal, 1993). By 6 weeks after the DRN lesion, no effect was observed for galanin, despite continued serotonergic depletion. This may reflect reinnervation, the inability to repeatedly detect this small signal, or long term variation in basal galanin concentrations in sham-operated rats. The coexistence of galanin and 5-HT within brainstem and spinal cord neurons has been noted for a decade (Skofitsch and Jacobowitz, 1985; Melander et al., 1986b). As might be expected from such a coexistence, evidence suggests that galanin modulates 5-HT metabolism and release (Fuxe et al., 1988; Martire et al., 1991). Further, galanin appears to modulate several autonomic responses that are mediated by 5-HT neurons (Fone and Dixon, 1991). A mechanism for the above effects is suggested by the unusual finding that galanin and $5-\mathrm{HT}_{1 \mathrm{a}}$ receptor agonists exert reciprocal noncompetitive interactions on the affinity of each others' receptors (Hedlund et al., 1991).

The acute increases in galanin concentrations after DRN lesions and the possible release of galanin after excitotoxin infu- 
sion are intriguing in light of recent observations. In many animal models, galanin gene expression is increased following neuronal injury (Cortes et al., 1990b; Unger and Schmidt, 1993; Zhang et al., 1993). Additionally, cerebral cortical galanin has been reported to be increased in postmortem tissues from Alzheimer's disease patients (Chan Palay, 1988b; Beal et al., 1990; Gabriel et al., 1994). Together with the present data, these observations suggest that galanin may be activated in a compensatory fashion in multiple systems after nerve damage. Galanin has been studied in relation to Alzheimer's disease because of its association with the cholinergic neurons whose degeneration is the hallmark of this disease. Although the failure of cortical galanin concentrations to also decline in this disease may reflect the absence of the peptide within NBM cholinergic neurons of humans, any low expression of galanin within these basal forebrain neurons would be difficult to detect given the multiple cortically projecting neurons that contain galanin, and the response of other neuronal systems, such as 5-HT, to nerve injury.

In summary, lesions of three subcortical nuclei produce effects on galanin concentrations in the rat cerebral cortex that vary by magnitude, time course and direction. The effects of these lesions suggest that the majority of cerebral cortical galanin is contained within cortically projecting efferents. Alternatively, these cortically projecting classical neurotransmittercontaining neurons may modulate or interact with intrinsic and other efferent galanin-containing cortical neurons. Interactions between cholinergic, noradrenergic, and serotonergic systems on learning and memory have been described (Haroutunian et al., 1990b; Markowska and Wenk, 1991; Connor et al., 1992; Dekker and Thal, 1993). Its widespread and overlapping distribution places galanin in a position to mediate interactions between neuronal systems during normal function. Such an interaction also may be particularly relevant to studies of neuronal injury and to human neurodegenerative conditions, such as Alzheimer's disease.

\section{References}

Austin MC, Cottingham SL, Paul SM, Crawley JN (1990) Tyrosine hydroxylase and galanin mRNA levels in locus coeruleus neurons are increased following reserpine administration. Synapse 6:351-357.

Beal MF, Clevens RA, Chattha GK, MacGarvey UM, Mazurek MF, Gabriel SM (1988) Galanin-like immunoreactivity is unchanged in Alzheimer's disease and Parkinson's disease dementia cerebral cortex. J Neurochem 51:1935-1941.

Beal MF, MacGarvey U, Swartz KJ (1990) Galanin immunoreactivity is increased in the nucleus basalis of Meynert in Alzheimer's disease. Ann Neurol 28:157-161.

Chan Palay V (1988a) Neurons with galanin innervate cholinergic cells in the human basal forebrain and galanin and acetylcholine coexist. Brain Res Bull 21:465-472

Chan Palay V (1988b) Galanin hyperinnervates surviving neurons of the human basal nucleus of Meynert in dementias of Alzheimer's and Parkinson's disease: a hypothesis for the role of galanin in accentuating cholinergic dysfunction in dementia. J Comp Neurol 273:543557.

Connor DJ, Dietz S, Langlais PJ, Thal LJ (1992) Behavioral effects of concurrent lesions of the nucleus basalis magnocellularis and the dorsal noradrenergic bundle. Exp Neurol 116:69-75.

Cortes R, Ceccatelli S, Schalling M, Hokfelt T (1990a) Differential effects of intracerebroventricular colchicine administration on the expression of mRNAs for neuropeptides and neurotransmitter enzymes, with special emphasis on galanin: an in situ hybridization study. Synapse 6:369-391.

Cortes R, Villar MJ, Verhofstad A, Hokfelt T (1990b) Effects of central nervous system lesions on the expression of galanin: a comparative in situ hybridization and immunohistochemical study. Proc Natl Acad Sci USA 87:7742-7746. de Bilbao F, Jazat F, Lamour Y, Senut MC (1991) Age-related changes in galanin-immunoreactive cells of the rat medial septal area. J Comp Neurol 313:613-624.

Dekker AJ, Thal LJ (1993) Independent effects of cholinergic and serotonergic lesions on acetylcholine and serotonin release in the neocortex of the rat. Neurochem Res 18:277-283.

Evans HF, Huntley GW, Morrison JH, Shine J, Paxinos G (1992) Localization of preprogalanin mRNA in the monkey hippocampal formation. Neurosci Lett 146:171-175.

Fibiger HC (1982) The organization and some projections of cholinergic neurons in the mammalian forebrain. Brain Res Rev 4:327388.

Fisone G, Wu CF, Consolo S, Nordstrom O, Brynne N, Bartfai T, Melander T, Hokfelt T (1987) Galanin inhibits acetylcholine release in the ventral hippocampus of the rat: histochemical, autoradiographic, in vivo, and in vitro studies. Proc Natl Acad Sci USA 84:7339-7343.

Fone KC, Dixon DM (1991) Acute and chronic effects of intrathecal galanin on behavioural and biochemical markers of spinal motor function in adult rats. Brain Res 544:118-125.

Fonnum FA (1975) Rapid radiochemical method of determination of choline acetyltransferase. J Neurochem 24:407-409.

Fuxe K, Ogren SO, Jansson A, Cintra A, Harfstrand A, Agnati LF (1988) Intraventricular injections of galanin reduces 5-HT metabolism in the ventral limbic cortex, the hippocampal formation and the fronto-parietal cortex of the male rat. Acta Physiol Scand 133:579581

Gabriel SM, Koenig JI, Washton DL (1993) Estrogen stimulation of galanin gene expression and galanin-like immunoreactivity in the rat and its blockade by the estrogen antagonist keoxifene (LY156758). Regul Pept 45:407-419.

Gabriel SM, Bierer LM, Davidson M, Purohit DP, Perl DP, Haroutunian $V$ (1994) Galanin-like immunoreactivity is increased in the postmortem cerebral cortex from patients with Alzheimer's disease. J Neurochem 62:1516-1523.

Gundlach AL, Rutherfurd SD, Louis WJ (1990a) Increase in galanin and neuropeptide $\mathrm{Y}$ mRNA in locus coeruleus following acute reserpine treatment. Eur J Pharmacol 184:163-167.

Gundlach AL, Wisden W, Morris BJ, Hunt SP (1990b) Localization of preprogalanin mRNA in rat brain: in situ hybridization study with a synthetic oligonucleotide probe. Neurosci Lett 114:241-247.

Haroutunian V, Kanof PD, Tsuboyama G, Davis KL (1990a) Restoration of cholinomimetic activity by clonidine in cholinergic plus noradrenergic lesioned rats. Brain Res 507:261-266.

Haroutunian V, Santucci AC, Davis KL (1990b) Implications of multiple transmitter system lesions for cholinomimetic therapy in $\mathrm{Al}$ zheimer's disease. Prog Brain Res 84:333-346.

Harrington CA, Mobley SL, Wenk GL (1994) Nitric oxide formation does not underlie the memory deficits produced by ibotenate injections into the nuclcus basalis of rats. Bchav Ncurosci 108:277-283.

Hedlund P, von Euler G, Fuxe K (1991) Activation of 5-hydroxytryptamine 1 A receptors increases the affinity of galanin receptors in diand telencephalic areas of the rat. Brain Res 560:251-259.

Hedreen JC, Struble RG, Whitehouse PJ, Price DL (1984) Topography of the magnocellular basal forebrain system in human brain. J Neuropathol Exp Neurol 43:1-21.

Johnson CD, Russell RL (1975) A rapid, simple radiometric assay for acetylcholinesterase, suitable for multiple determinations. Anal Biochem 65:229-232.

Johnston MV, McKinney M, Coyle JT (1981) Neocortical cholinergic innervation: a description of extrinsic and intrinsic components in the rat. Exp Brain Res 43:159-172.

Kitchener PD, Diamond J (1993) Distribution and colocalization of choline acelyltransferase inmmunoreactivity and NADPH diaphorase reactivity in neurons within the medial septum and diagonal band of Broca in the rat basal forebrain. J Comp Neurol 335:1-15.

Kowall NW, Beal MF (1989) Galanin-like immunoreactivity is present in human substantia innominata and in senile plaques in Alzheimer's disease. Neurosci Lett 98:118-123.

Leibowitz SF (1989) Hypothalamic neuropeptide Y, galanin, and amines. Concepts of coexistence in relation to feeding behavior. Ann NY Acad Sci 575:221-233.

Levin MC, Sawchenko PE, Howe PR, Bloom SR, Polak JM (1987) Organization of galanin-immunoreactive inputs to the paraventricular nucleus with special reference to their relationship to catecholaminergic afferents. J Comp Neurol 261:562-582. 
Lowry OH, Rorebrough NJ, Farr AL, Randall RJ (1951) Protein measurement with folin reagent. J Biol Chem 193:265-272.

Markowska AL, Wenk GL (1991) Serotonin influences the behavioral recovery of rats following nucleus basalis lesions. Pharmacol Biochem Behav 38:731-737.

Martire M, Fuxe K, Agnati LF, Pistritto G, Preziosi P (1991) Galanin increases potassium evoked release of $\left[{ }^{3} \mathrm{H}\right] 5$-hydroxytryptamine from rat hypothalamic synaptosomal preparations. Neurosci Lett 122:8790.

Mastropaolo J, Nadi NS, Ostrowski NL, Crawley JN (1988) Galanin antagonizes acetylcholine on a memory task in basal forebrain-lesioned rats. Proc Natl Acad Sci USA 85:9841-9845.

Melander T, Staines WA, Hokfelt T, Rokaeus A, Eckenstein F, Salvaterra PM, Wainer BH (1985) Galanin-like immunoreactivity in cholinergic neurons of the septum-basal forebrain complex projecting to the hippocampus of the rat. Brain Res 360:130-138.

Melander T, Hokfelt T, Rokaeus A (1986a) Distribution of galaninlike immunoreactivity in the rat central nervous system. J Comp Neurol 248:475-517.

Melander T, Hokfelt T, Rokaeus A, Cuello AC, Oertel WH, Verhofstad A, Goldstein M (1986b) Coexistence of galanin-like immunoreactivity with catecholamines, 5-hydroxytryptamine, GABA and neuropeptides in the rat CNS. J Neurosci 6:3640-3654.

Mufson EJ, Cochran E, Benzing W, Kordower JH (1993) Galaninergic innervation of the cholinergic vertical limb of the diagonal band (Ch2) and bed nucleus of the stria terminalis in aging, Alzheimer's disease and Down's syndrome. Dementia 4:237-250.

Nieuwenhuys R (1985) Chemoarchitecture of the brain. Berlin: Springer.

Pasqualotto BA, Vincent SR (1991) Galanin and NADPH-diaphorase coexistence in cholinergic neurons of the rat basal forebrain. Brain Res 551:78-86.

Robinson JK, Crawley JN (1993) The role of galanin in cholinergically-mediated memory processes. Prog Neuropsychopharmacol Biol Psychiatry 17:71-85.

Schultzberg M, Austin MC, Crawley JN, Paul SM (1991) Repeated administration of desmethylimipramine blocks the reserpine-induced increase in tyrosine hydroxylase mRNA in locus coeruleus neurons of the rat. Brain Res Mol Brain Res 10:307-314.

Senut MC, Menetrey D, Lamour Y (1989) Cholinergic and peptidergic projections from the medial septum and the nucleus of the diagonal band of Broca to dorsal hippocampus, cingulate cortex and olfactory bulb: a combined wheatgerm agglutinin-apohorseradish peroxidasegold immunohistochemical study. Neuroscience 30:385-403.

Seutin V, Verbanck P, Massotte L, Dresse A (1989) Galanin decreases the activity of locus coeruleus neurons in vitro. Eur J Pharmacol 19; $164: 373-376$.

Skofitsch G, Jacobowitz DM (1985) Immunohistochemical mapping of galanin-like neurons in the rat central nervous system. Peptides 6:509-546.

Tatemoto K, Rokaeus A, Jornvall H, McDonald TJ, Mutt V (1983) Galanin-a novel biologically active peptide from porcine intestine. FEBS Lett 164:124-128.

Unger JW, Schmidt Y (1993) Galanin-immunoreactivity in the nucleus basalis of Meynert in the rat: age-related changes and differential response to lesion-induced cholinergic cell loss. Neurosci Lett 153: 140-143.

Walker LC, Koliatsos VE, Kitt CA, Richardson RT, Rokaeus A, Price DL (1989) Peptidergic neurons in the basal forebrain magnocellular complex of the rhesus monkey. J Comp Neurol 280:272-282.

Walker LC, Rance NE, Price DL, Young WS (1991) Galanin mRNA in the nucleus basalis of Meynert complex of baboons and humans. J Comp Neurol 303:113-120.

Wenk GL, Rokaeus A (1988) Basal forebrain lesions differentially alter galanin levels and acetylcholinergic receptors in the hippocampus and neocortex. Brain Res 460:17-21.

Xu Z, Cortes R, Villar M, Morino P, Castel MN, Hokfelt T (1992) Evidence for upregulation of galanin synthesis in rat glial cells in vivo after colchicine treatment. Neurosci Lett 145:185-188.

Zhang X, Verge VM, Wiesenfeld Hallin Z, Piehl F, Hokfelt T (1993) Expression of neuropeptides and neuropeptide mRNAs in spinal cord after axotomy in the rat, with special reference to motoneurons and galanin. Exp Brain Res 93:450-461. 